\title{
Correlated Factors with Quitting Attempts Among Male Smokers in Vietnam: A QUITLINE-Based Survey
}

\author{
Chau Quy Ngo ${ }^{1}$, Ryan G. Chiu ${ }^{2,3} \mathbb{C}^{\text {, Hanh Thi Chu }}{ }^{1}$, Giap Van Vu ${ }^{1}$, Quang Nhat Nguyen ${ }^{4,5}$, \\ Long Hoang Nguyen ${ }^{6}$, Tung Thanh Tran ${ }^{5}$, Cuong Tat Nguyen ${ }^{7}$, Bach Xuan Tran ${ }^{8,9, *(\mathbb{O})}$, \\ Carl A. Latkin ${ }^{9}$, Cyrus S.H. Ho ${ }^{10}$ and Roger C.M. Ho ${ }^{6,11}$
}

1 Department of Internal Medicine, Hanoi Medical University, Hanoi 100000, Vietnam; ngoquychaubmh@gmail.com (C.Q.N.); chuthihanhbmh@gmail.com (H.T.C.); vuvangiap@hmu.edu.vn (G.V.V.)

11 Department of Psychological Medicine, Yong Loo Lin School of Medicine, National University of Singapore, Singapore 119077, Singapore

* Correspondence: bach.ipmph@gmail.com; Tel.: +84-982-228-662

Received: 20 November 2018; Accepted: 18 December 2018; Published: 30 December 2018

\begin{abstract}
Despite its decreasing prevalence, cigarette smoking remains the second leading cause of preventable death worldwide. In Vietnam, despite recent smoking cessation efforts, the prevalence of tobacco consumption remains high, particularly among males. In this study, we aim to evaluate the self-efficacy in quitting smoking (i.e., quitting confidence), intention to quit, and identifying associated factors among both rural and urban Vietnamese male populations. A cross-sectional study was conducted on 321 patients (52.7\% urban and $47.4 \%$ rural inhabitants) who utilized QUITLINE services of Bach Mai Hospital (Hanoi, Vietnam). Socio-economic status, smoking history, cigarette usage data, and intent to quit were assessed. Baseline data were correlated with quitting confidence, to identify significant associated factors. The majority $(75.9 \%)$ of participants were in the planning phase of cessation, yet $90.8 \%$ lacked complete confidence in their quitting ability. Older age, fewer cigarettes per day and previous quitting attempts were associated with quitting confidence $(p<0.05)$ and plans to quit $(p<0.05)$. Older smokers and previous quitters were more confident in their ability to quit in the near future and more likely to have made plans to quit. Future smoking cessation efforts should focus on improving self-efficacy, particularly among younger and newer smokers.
\end{abstract}

Keywords: smoking; quitting; attempt; quitline; Vietnam 


\section{Introduction}

Smoking remains the second leading cause of early death and disability worldwide, resulting in 10 million lives lost annually and USD 1.9 trillion in lost productivity, wages and healthcare expenditure worldwide [1-4]. It is also estimated that the age-adjusted prevalence of daily tobacco smoking is $31.1 \%$ for men and $6.2 \%$ for women [5]. Furthermore, as a global average, roughly $50 \%$ of young men and $10 \%$ of young women are projected to become smokers in their lifetime if current prevalence figures persist $[3,5]$.

Recognizing the tremendous benefits of smoking cessation, an increasing number of national smoking cessation initiatives have been carried out including the taxation of cigarettes and other tobacco products, restrictions on their marketing and promotion, bans on their consumption in public venues, and the mandated placement of warning labels on sold items [1]. Nevertheless, the impact of such programs has been inconsistent and variable among countries [6]. In developing countries, including Vietnam, socio-economic factors and the resulting lack of access to quitlines and the availability of other cessation services, remain key obstacles to the effective promotion of smoking cessation [6]. Moreover, the lack of policy and public awareness surrounding the risks associated with cigarette use, in addition to industry influence, further impede progress [6-8]. It follows that even as assistance becomes more readily available in these countries, the rates of use of such services have been significantly underutilized in comparison with more developed nations [9].

In Vietnam, a series of public health reforms, including the utilization of village health workers as community health promoters and smoking cessation counselors, have contributed to the decline in tobacco use since the 1990s [10-12]. Of note are QUITLINE services, which are nationally standardized, locally administered, toll-free, phone-based systems for tobacco abuse education offering support for those planning to quit smoking and maintenance support for those who have already ceased smoking [10]. These programs have formed a relatively low-cost and integral part of cessation services across the country. Most, however, are currently managed separately by individual healthcare institutions and require consolidation from the Vietnamese government to equalize standards of care and information provided to clients [10]. As a result, despite the implementation of the aforementioned policies, the prevalence of smoking among Vietnamese males remains high (45.3\%) [13]. Furthermore, while data are available regarding cessation and cessation attempt rates [13], studies examining potential correlates to smoking cessation intention and self-efficacy remain limited.

Self-efficacy has been proposed in some behavioral theories such as the transtheoretical model, the theory of planned behavior or the health belief model as a critical component for the success of smoking cessation. Increasing self-efficacy may motivate the initiation and maintenance of smoking cessation, as well as relapse prevention [14]. In this study, we aim to evaluate the self-efficacy in quitting smoking (i.e., quitting confidence), intention to quit and identify associated factors among both rural and urban Vietnamese male populations. Smoking prevalence among males in Vietnam is one of the highest in the world. A greater understanding of the potential correlates of smoking cessation success might provide important insights for future health policy reform and community efforts to support and sustain the impact of smoking cessation initiatives in Vietnam.

\section{Materials and Methods}

\subsection{Study Design and Sampling}

We conducted a cross-sectional study from June to July 2016 at the Respiratory Center at Bach Mai Hospital where the QUITLINE service was established in September 2015 to support tobacco users to quit tobacco use. The service, which was provided by 10 consultants certified in counseling drug treatment, is available to patients every day of the week from 8:00 a.m. to 10:00 p.m. free-of-charge.

Convenience sampling was utilized to recruit a total of 321 male participants according to the following inclusion criteria: (1) being at least 18 years of age, (2) having contacted the QUITLINE service to schedule an appointment, and (3) being available to participate in a 5- to 10-minute phone 
interview. All participants were informed of the study risks and benefits and the protection of their confidentiality prior to their participation in the study.

\subsection{Measurements and Instruments}

Participants contacting the QUITLINE service were initially invited to participate in the survey using a structured questionnaire before receiving counseling services. Participant information about socio-economic characteristics (age, education, employment, and living area), cigarette consumption patterns (types of cigarette and daily frequency of usage), history of smoking cessation, and motivation to quit smoking were collected via closed-ended questions.

\subsubsection{History of Smoking Cessation}

Participants history of smoking cessation attempts were collected. This history recorded attempts to quit smoking in the past year (prior to contacting the QUITLINE service, the number of cigarettes consumed after attempting to quit and the duration of smoking abstinence if applicable.

\subsubsection{Motivation to Quit Smoking}

Participants were asked about their plans (if any) to quit smoking in the next year. They were also asked to assess their confidence in being able to quit smoking on a scale from 0 to 10 points, with a score of 10 indicating complete confidence in one's ability to successfully quit smoking. This scale was adapted from recommendations by the Mayo Clinic for quantifying cessation confidence [15].

\subsection{Statistical Analysis}

The data were analyzed using STATA version 12.0 (Stata Corp. LP, College Station, TX, USA). Chi-square and Mann-Whitney $U$-tests were conducted to compare socio-economic data, history of smoking cessation and motivation to quit smoking by living area (rural or urban), to determine if participants differed significantly by geographic origin, before identifying factors associated with our primary endpoints. Multivariate logistic regression was then employed to identify factors associated with a motivation to quit in the next year and complete confidence in quitting smoking, controlling for any significant baseline differences in demographic variables between rural and urban participants. A multivariate Tobit regression was used to assess factors associated with the smoking cessation confidence score. A pool of variables was used as potential associated factors with outcomes of interest, including socio-demographic characteristics (age, marital status, education, employment), smoking behaviors (type of cigarettes used, number of cigarettes use per day), and history of smoking cessation (attempts to quit smoking before contacting the QUITLINE service, attempts to quit last year). Stepwise backward strategies were combined with these regression models, using the $p$-value of log-likelihood of 0.2 as the threshold for selecting the variables, to construct the final models. Statistical significance was set at $p<0.05$.

\subsection{Ethics Approval}

The protocol of the study was approved by the Institutional Review Board of Bach Mai Hospital.

\section{Results}

Among the 321 male participants, roughly half resided in rural areas (52.7\%). Most were married $(81.6 \%)$, had obtained high school education (52\%), and were blue-collar workers $(41.7 \%)$. Regarding cigarette usage pattern, $95 \%$ of the participants utilized standard cigarettes with the median number of daily cigarette consumption per day being 13.8 (25th-75th percentile: 7-20) (Table 1). 
Table 1. Socio-economic characteristic of the participants.

\begin{tabular}{|c|c|c|c|c|c|c|c|}
\hline \multirow{3}{*}{ Characteristic } & \multicolumn{4}{|c|}{ Living Area } & & & \multirow{3}{*}{$p$-Value } \\
\hline & \multicolumn{2}{|c|}{ Rural } & \multicolumn{2}{|c|}{ Urban } & \multicolumn{2}{|c|}{ Total } & \\
\hline & $n$ & $\%$ & $n$ & $\%$ & $n$ & $\%$ & \\
\hline Total & 169 & 52.7 & 152 & 47.4 & 321 & 100 & \\
\hline Age group (years) & & & & & & & 0.04 \\
\hline$<30$ & 37 & 21.9 & 42 & 27.6 & 79 & 24.6 & \\
\hline $30-44$ & 70 & 41.4 & 57 & 37.5 & 127 & 39.6 & \\
\hline $45-59$ & 50 & 29.6 & 31 & 20.4 & 81 & 25.2 & \\
\hline $60+$ & 12 & 7.1 & 22 & 14.5 & 34 & 10.6 & \\
\hline Marital status & & & & & & & 0.38 \\
\hline Single & 28 & 16.6 & 31 & 20.4 & 59 & 18.4 & \\
\hline Married & 141 & 83.4 & 121 & 79.6 & 262 & 81.6 & \\
\hline Education & & & & & & & $<0.01$ \\
\hline Below high school & 69 & 40.8 & 28 & 18.4 & 97 & 30.2 & \\
\hline High school & 79 & 46.8 & 88 & 57.9 & 167 & 52.0 & \\
\hline Above high school & 21 & 12.4 & 36 & 23.7 & 57 & 17.8 & \\
\hline Employment & & & & & & & $<0.01$ \\
\hline Blue-collar workers & 87 & 51.5 & 47 & 30.9 & 134 & 41.7 & \\
\hline White-collar workers & 21 & 12.4 & 28 & 18.4 & 49 & 15.3 & \\
\hline No income & 26 & 15.4 & 39 & 25.7 & 65 & 20.3 & \\
\hline Others & 35 & 20.7 & 38 & 25.0 & 73 & 22.7 & \\
\hline \multicolumn{8}{|l|}{ Type of cigarette used } \\
\hline Standard cigarette & 160 & 94.7 & 145 & 95.4 & 305 & 95.0 & 0.77 \\
\hline Rolling tobacco & 2 & 1.2 & 3 & 2.0 & 5 & 1.6 & 0.57 \\
\hline Bamboo water pipe & 16 & 9.5 & 19 & 12.5 & 35 & 10.9 & 0.38 \\
\hline Number of cigarettes/day & & & & & & & 0.05 \\
\hline$<10$ & 51 & 32.1 & 35 & 24.1 & 86 & 28.3 & \\
\hline $10-19$ & 51 & 32.1 & 49 & 33.8 & 100 & 32.9 & \\
\hline $20-29$ & 54 & 34.0 & 49 & 33.8 & 103 & 33.9 & \\
\hline \multirow[t]{2}{*}{$30+$} & 3 & 1.9 & 12 & 8.3 & 15 & 4.9 & \\
\hline & Median & 25 th -75 & Median & 25 th-75t & Median & 25th-75th & \\
\hline Age (years) & 40 & $31-49$ & 37.5 & $29-51.5$ & 39 & $30-50$ & 0.73 \\
\hline Number of cigarettes/day & 13 & $7-20$ & 13.8 & $10-20$ & 13.4 & $7-20$ & 0.27 \\
\hline
\end{tabular}

Among study participants, we observed that a high percentage $(79.8 \%)$ had attempted to quit smoking in the last year before contacting the QUITLINE service (Table 2). After attempting to quit, $76.2 \%$ of them reported not smoking another cigarette. However, the duration of their smoking abstinence remains low at 0.27 months. The methods used to quit smoking among these participants were highly variable (i.e., non-nicotine gum, oral medications, counseling, or a combination thereof).

Table 3 illustrates the motivation to quit smoking among participants. Most of them (75.9\%) reported wanting to quit smoking in the coming year. However, only $9.2 \%$ were completely confident about quitting smoking, with a mean quit smoking confidence score of 6.7 (Standard deviation $(\mathrm{SD})=2.3$ ). A high proportion of participants reported having received support from relatives/friends $(65.6 \%)$ or their spouses/partners $(69.6 \%)$. Importantly, the most common reasons for reported smoking relapse were being around people who smoked $(63.9 \%)$, and feeling uncomfortable if not smoking (55.0\%). 
Table 2. History of smoking cessation.

\begin{tabular}{|c|c|c|c|c|c|c|c|}
\hline \multirow{3}{*}{ Characteristic } & \multicolumn{4}{|c|}{ Living Place } & & & \multirow{3}{*}{$p$-Value } \\
\hline & \multicolumn{2}{|c|}{ Rural } & \multicolumn{2}{|c|}{ Urban } & \multicolumn{2}{|c|}{ Total } & \\
\hline & $n$ & $\%$ & $n$ & $\%$ & $n$ & $\%$ & \\
\hline $\begin{array}{c}\text { Tried to quit smoking before contacting } \\
\text { QUITLINE service }\end{array}$ & & & & & & & 0.62 \\
\hline No & 36 & 21.3 & 29 & 19.1 & 65 & 20.3 & \\
\hline Yes & 133 & 78.7 & 123 & 80.9 & 256 & 79.8 & \\
\hline Attempted to quit in the last 12 months & & & & & & & 0.74 \\
\hline No & 41 & 24.7 & 40 & 26.3 & 81 & 25.5 & \\
\hline Yes & 125 & 75.3 & 112 & 73.7 & 237 & 74.5 & \\
\hline $\begin{array}{c}\text { Total number of cigarettes smoked after } \\
\text { attempting to quit }\end{array}$ & & & & & & & 0.83 \\
\hline None & 103 & 77.4 & 92 & 74.8 & 195 & 76.2 & \\
\hline 1-5 cigarettes & 16 & 12.0 & 18 & 14.6 & 34 & 13.3 & \\
\hline More than 5 cigarettes & 14 & 10.5 & 13 & 10.6 & 27 & 10.6 & \\
\hline Methods used to quit smoking & & & & & & & \\
\hline Direct counseling & 1 & 0.8 & 2 & 1.6 & 3 & 1.2 & 0.52 \\
\hline Nicotine replacement therapy & 2 & 1.5 & 3 & 2.4 & 5 & 2.0 & 0.59 \\
\hline Using non-nicotine gum & 9 & 6.8 & 12 & 9.8 & 21 & 8.2 & 0.38 \\
\hline Use medicine (Bupropion/Varenicline) & 6 & 4.5 & 6 & 4.9 & 12 & 4.7 & 0.89 \\
\hline Not using any method & 8 & 6.0 & 6 & 4.9 & 14 & 5.5 & 0.69 \\
\hline \multirow[t]{2}{*}{ Others } & 1 & 0.8 & 0 & 0.0 & 1 & 0.4 & 0.34 \\
\hline & \multicolumn{7}{|c|}{ Median 25th-75tMedian 25th-75tMedian 25th-75th } \\
\hline Duration of smoking abstinence (months) & 0.2 & $0.06-2.8$ & 0.4 & $0.07-12$ & 0.27 & $0.07-12$ & 0.55 \\
\hline
\end{tabular}

Table 3. Attempts to quit smoking.

\begin{tabular}{|c|c|c|c|c|c|c|c|}
\hline \multirow{3}{*}{ Characteristic } & \multicolumn{4}{|c|}{ Living Place } & & & \multirow{3}{*}{$p$-Value } \\
\hline & \multicolumn{2}{|c|}{ Rural } & \multicolumn{2}{|c|}{ Urban } & \multicolumn{2}{|c|}{ Total } & \\
\hline & $n$ & $\%$ & $n$ & $\%$ & $n$ & $\%$ & \\
\hline \multicolumn{8}{|l|}{ Planning to quit in the coming years } \\
\hline No & 37 & 21.9 & 40 & 26.7 & 77 & 24.1 & 0.32 \\
\hline Yes & 132 & 78.1 & 110 & 73.3 & 242 & 75.9 & \\
\hline \multicolumn{8}{|l|}{ Quitting confidence } \\
\hline Not completely confident & 125 & 89.9 & 112 & 91.8 & 237 & 90.8 & 0.60 \\
\hline Completely confident & 14 & 10.1 & 10 & 8.2 & 24 & 9.2 & \\
\hline \multicolumn{8}{|l|}{ Received support from } \\
\hline Relatives, friends & 85 & 65.9 & 75 & 65.2 & 160 & 65.6 & 0.91 \\
\hline Spouses/partners & 88 & 68.2 & 81 & 71.1 & 169 & 69.6 & 0.63 \\
\hline \multicolumn{8}{|l|}{ Reasons for smoking relapse } \\
\hline Feeling uncomfortable & 69 & 53.9 & 64 & 56.1 & 133 & 55.0 & 0.73 \\
\hline People around smoking & 85 & 66.9 & 69 & 60.5 & 154 & 63.9 & 0.30 \\
\hline Stress at work & 42 & 32.8 & 51 & 45.1 & 93 & 38.6 & 0.05 \\
\hline Weight gain & 5 & 3.9 & 3 & 2.6 & 8 & 3.3 & 0.58 \\
\hline \multirow[t]{2}{*}{ Others } & 21 & 16.4 & 11 & 9.7 & 32 & 13.2 & 0.12 \\
\hline & Mean & SD & Mean & SD & Mean & SD & \\
\hline Quit smoking confidence (score) & 6.7 & 2.3 & 6.6 & 2.3 & 6.7 & 2.3 & 0.66 \\
\hline
\end{tabular}

Table 4 summarizes the factors associated with quitting confidence and planning to quit in the next year. We found that the higher the quit smoking confidence score of the participant, the more likely he/she planned to quit smoking in the coming year (Odds Ratio (OR) = 1.30, 95\% Confident Interval $(\mathrm{CI})=1.04,1.62)$. Older participants were also likely to have more confidence in quitting 
smoking $(\mathrm{OR}=1.05,95 \% \mathrm{CI}=1.02,1.09)$. Importantly, the number of cigarettes per day had a negative association with the confidence of being able to quit smoking ( $\mathrm{OR}=0.94,95 \% \mathrm{CI}=0.89,<1.00)$. Lastly, the participants who tried to quit smoking in the last year were more likely to have a higher quit smoking confidence score (coeficient $=0.80,95 \% \mathrm{CI}=0.01,1.58$ ). Marital status, educational attainment level, living area, and previous self-managed attempts to quit were not associated with one's confidence to successfully quit or having a plan to quit smoking.

Table 4. Associated factors with quitting attempts and quitting confidence.

\begin{tabular}{|c|c|c|c|c|c|c|}
\hline \multirow[t]{2}{*}{ Characteristic } & \multicolumn{2}{|c|}{$\begin{array}{c}\text { Completely Confident } \\
\text { of Quitting }\end{array}$} & \multicolumn{2}{|c|}{$\begin{array}{l}\text { Quit Smoking } \\
\text { Confidence (Score) }\end{array}$} & \multicolumn{2}{|c|}{$\begin{array}{l}\text { Planning to Quit in the } \\
\text { Coming Years }\end{array}$} \\
\hline & OR & $95 \%$ CI & Coef. & $95 \% \mathrm{CI}$ & OR & $95 \% \mathrm{CI}$ \\
\hline Quitting confidence (score) & & & & & $1.30 * *$ & $1.04,1.62$ \\
\hline Age & $1.05^{* * *}$ & $1.02,1.09$ & $0.04^{* * *}$ & $0.02,0.07$ & & \\
\hline \multicolumn{7}{|l|}{ Marital status } \\
\hline Single & ref & & ref & & & \\
\hline Married & 0.41 & $0.11,1.52$ & -0.67 & $-1.53,0.19$ & & \\
\hline \multicolumn{7}{|l|}{ Education } \\
\hline Below high school & ref & & & & ref & \\
\hline Above high school & 0.37 & $0.08,1.69$ & & & 4.55 & $0.56,37.01$ \\
\hline \multicolumn{7}{|l|}{ Living area } \\
\hline Rural & & & & & ref & \\
\hline Urban & & & & & 0.45 & $0.15,1.36$ \\
\hline \multicolumn{7}{|l|}{$\begin{array}{l}\text { Tried to quit smoking before } \\
\text { contacting QUITLINE service }\end{array}$} \\
\hline No & ref & & & & & \\
\hline Yes & 0.36 & $0.08,1.62$ & & & & \\
\hline Number of cigarettes per day & $0.94^{* *}$ & $0.89,<1.00$ & $-0.03^{* *}$ & $\begin{array}{l}-0.06 \\
<-0.00\end{array}$ & & \\
\hline \multicolumn{7}{|l|}{ Attempted to quit last year } \\
\hline No & & & ref & & & \\
\hline Yes & & & $0.80 * *$ & $0.01,1.58$ & & \\
\hline
\end{tabular}

\section{Discussion}

In Vietnam, smoking cessation initiatives that have shown success in other countries, have suffered not only from a relative scarcity of funding and government support but also from a lack of consolidation around evidence-based guidelines [2,10]. In this study, we found that participants' age and previous quit attempts were positively associated with confidence in one's ability to cease smoking in the next year, and that conversely, the number of cigarettes one consumed per day was negatively associated with this outcome. It also follows that confidence, as assessed by the 12-point confidence scale, was positively correlated with having a plan to quit within the next year. It should be noted that although the cross-sectional nature of this study is unable to determine the order of correlated events, previous literature suggests that self-efficacy precedes intention and attempts to quit, rather than vice versa [16]. These findings may serve as a basis upon which future national standards, and additional public policy, may be better informed, through a greater focus on fostering the aforementioned sense of confidence and self-efficacy among younger and/or newer quitters.

While the association between previous cessation attempts and perceived future cessation ability is widely supported by the available literature, the positive relationship between age and quitting confidence conflicts with some reports from other countries [17]. Some of these argue that older patients are less likely to attempt to quit smoking compared to their younger counterparts, while others vice versa [18-21]. Nonetheless, this study serves as the first to evaluate the strength of age as a correlate to smoking cessation readiness in a strictly Vietnamese population. 
The observed association may be due to the fact that many clinical sequelae associated with tobacco use, such as cardiovascular disease and lung cancers, do not manifest until use has become chronic [2]. It follows, that in witnessing first-hand the negative effects of smoking, patients may then become more motivated to quit as a result. This may, in turn, be compounded by the fact that information regarding the adverse effects associated with smoking have not traditionally been as widely disseminated in Vietnam compared to Western countries, where anti-smoking campaigns have long been propagated through: government policy/regulation, philanthropic endeavors, mass media, and scholastic drug abuse education programs [22]. As a result, asymptomatic Vietnamese smokers and those contemplating becoming smokers may not be as aware of the long-term adverse health outcomes compared to their Western counterparts. In addition, cultural factors particularly salient among Vietnamese males may compound these effects, as smoking has long been seen as an integral part of male social status and activity [23]. Nevertheless, the manifestation of symptoms of chronic smoking in late life, combined with increasing lifespans and an aging population, creates additional economic and healthcare burdens that should be addressed by future public policy and the adoption of evidence-based standards.

The negative association between smoking frequency (in terms of cigarettes per day) and participants' confidence scores are not particularly surprising, as the relationship between the frequency of tobacco consumption and cessation confidence is well-documented in the literature [24-27]. Furthermore, the correlation between higher confidence in cessation and being in the planning phase of cessation also supports findings from previous studies [28-32]. Nevertheless, these findings also indicate the need for greater focus on identifying and encouraging those smokers who are in the earlier stages of addiction (i.e., those who may not currently smoke as many cigarettes per day as those who have a long smoking history), to quit sooner rather than later.

The implications of the results of this study on Vietnamese public health policy point to the creation of policies that foster the promotion of positive correlates in the planning phase of smoking cessation. Namely, approaches and strategies that boost quitting confidence and lower the frequency of cigarette consumption may prove fruitful in increasing quitting success rates in these populations. Furthermore, our results suggest that additional support might be needed for younger smokers and smokers with no previous history of quitting attempts, as they were found to be less likely to possess the necessary self-confidence in smoking cessation, and less likely to be in the planning phase of quitting. For example, future efforts could focus on providing active encouragement to individuals contemplating quitting, enhancing self-efficacy and boosting willpower in line with the cultural values of many Vietnamese individuals, who often cite personal will as "all it takes" to overcome addiction [33]. The behavioral support that these actions offer may bolster the positive and negative reinforcement of smoking cessation, and thus increase the rate at which quit attempts are made, and ultimately succeed [34].

\section{Limitations}

Despite roughly equal representation of participants from both urban and rural settings, as a single-center study, the patient population eligible and available for inclusion in our study may not be fully representative of the Vietnamese population as a whole. Additionally, the entirely male population of the study serves as a limitation to the external validity of this study on the general population. However, given the stark differences in cultural expectations and behaviors between Vietnamese males and females, the results presented here are applicable to the creation of effective policies and interventions targeting males in particular, among whom smoking remains far more common than in females [23]. Moreover, the existence of stigmas surrounding smoking and its cessation may have caused either under or over self-reporting of some information in the interview [35].

Lastly, it is important to note that the participants within this study are individuals who were willing to call the QUITLINE service. Consequently, the factors correlated with smoking cessation confidence in this study may not be the same for those smokers who were not as motivated, or who 
are otherwise unwilling or unable to contact QUITLINE. Nonetheless, as contemplation is only one step toward actualization of smoking cessation, identifying factors associated with quitting among contemplative individuals might help us better focus resources in the development of more targeted and effective programs to decrease smoking prevalence.

\section{Conclusions}

Among Vietnamese male smokers, older age and previous attempts to quit were positively associated with confidence in one's own ability to quit in the near future. It follows, that future policies and interventions aimed at reducing the prevalence of smoking, should be designed in order to better help younger smokers and those in the pre-contemplative phase of smoking cessation to better formulate plans to quit in the near future, and boost confidence in their ability to overcome addiction.

Author Contributions: Data curation, C.Q.N., R.G.C., H.T.C., G.V.V., Q.N.N. and C.S.H.H.; Formal analysis, C.Q.N. and C.T.N.; Methodology, C.Q.N., R.G.C., H.T.C., Q.N.N., B.X.T. and R.C.M.H.; Project administration, C.Q.N. and T.T.T.; Resources, C.Q.N. and L.H.N.; Supervision, R.G.C.; Validation, R.G.C.; Visualization, C.A.L.; Writing一original draft, C.Q.N., R.G.C., H.T.C., G.V.V., Q.N.N., L.H.N., T.T.T., C.T.N., B.X.T., C.A.L., C.S.H.H. and R.C.M.H.; Writing-review \& editing, C.Q.N., H.T.C., G.V.V., Q.N.N., L.H.N., T.T.T., C.T.N., B.X.T., C.A.L., C.S.H.H. and R.C.M.H.

Funding: The authors received no funding for this study.

Conflicts of Interest: The authors declare no conflict of interest.

\section{References}

1. GBD 2015 Risk Factors Collaborators. Global, regional, and national comparative risk assessment of 79 behavioural, environmental and occupational, and metabolic risks or clusters of risks, 1990-2015: A systematic analysis for the Global Burden of Disease Study 2015. Lancet 2016, 388, 1659-1724. [CrossRef]

2. GBD 2015 Tobacco Collaborators. Smoking prevalence and attributable disease burden in 195 countries and territories, 1990-2015: A systematic analysis from the Global Burden of Disease Study 2015. Lancet 2017, 389, 1885-1906. [CrossRef]

3. Jha, P.; Peto, R. Global effects of smoking, of quitting, and of taxing tobacco. N. Engl. J. Med. 2014, 370, 60-68. [CrossRef] [PubMed]

4. Goodchild, M.; Nargis, N.; Tursan d'Espaignet, E. Global economic cost of smoking-attributable diseases. Tob. Control 2018, 27, 58-64. [CrossRef] [PubMed]

5. Ng, M.; Freeman, M.K.; Fleming, T.D.; Robinson, M.; Dwyer-Lindgren, L.; Thomson, B.; Wollum, A.; Sanman, E.; Wulf, S.; Lopez, A.D.; et al. Smoking prevalence and cigarette consumption in 187 countries, 1980-2012. JAMA 2014, 311, 183-192. [CrossRef] [PubMed]

6. Abdullah, A.S.; Husten, C.G. Promotion of smoking cessation in developing countries: A framework for urgent public health interventions. Thorax 2004, 59, 623-630. [CrossRef]

7. Yang, G.; Fan, L.; Tan, J.; Qi, G.; Zhang, Y.; Samet, J.M.; Taylor, C.E.; Becker, K.; Xu, J. Smoking in China: Findings of the 1996 National Prevalence Survey. JAMA 1999, 282, 1247-1253. [CrossRef] [PubMed]

8. Farrelly, M.C.; Healton, C.G.; Davis, K.C.; Messeri, P.; Hersey, J.C.; Haviland, M.L. Getting to the truth: Evaluating national tobacco countermarketing campaigns. Am. J. Public Health 2002, 92, 901-907. [CrossRef] [PubMed]

9. Wang, L.; Jin, Y.; Lu, B.; Ferketich, A.K. A Cross-Country Study of Smoking Cessation Assistance Utilization in 16 Low and Middle Income Countries: Data From the Global Adult Tobacco Survey (2008-2012). Nicotine Tob. Res. 2016, 18, 1076-1082. [CrossRef] [PubMed]

10. Minh, H.V.; Ngan, T.T.; Mai, V.Q.; My, N.T.; Chung le, H.; Kien, V.D.; Anh, T.T.; Ngoc, N.B.; Giap, V.V.; Cuong, N.M.; et al. Tobacco Control Policies in Vietnam: Review on MPOWER Implementation Progress and Challenges. Asian Pac. J. Cancer Prev. 2016, 17, 1-9. [PubMed]

11. Bui, T.V.; Blizzard, L.; Luong, K.N.; Truong Nle, V.; Tran, B.Q.; Ha, S.T.; Phung, H.N.; Otahal, P.; Velandai, S.; Nelson, M.R.; et al. Declining Prevalence of Tobacco Smoking in Vietnam. Nicotine Tob. Res. 2015, 17, 831-838. [CrossRef] [PubMed] 
12. Nguyen, N.; Nguyen, T.; Chapman, J.; Nguyen, L.; Kumar, P.; VanDevanter, N.; Shelley, D. Tobacco cessation in Vietnam: Exploring the role of village health workers. Glob. Public Health 2018, 13, 1265-1275. [CrossRef] [PubMed]

13. Van Minh, H.; Giang, K.B.; Ngoc, N.B.; Hai, P.T.; Huyen, D.T.; Khue, L.N.; Lam, N.T.; Nga, P.T.; Quan, N.T.; Xuyen, N.T. Prevalence of tobacco smoking in Vietnam: Findings from the Global Adult Tobacco Survey 2015. Int. J. Public Health 2017, 62, 121-129. [CrossRef] [PubMed]

14. Gwaltney, C.J.; Metrik, J.; Kahler, C.W.; Shiffman, S. Self-efficacy and smoking cessation: A meta-analysis. Psychol. Addict. Behav. 2009, 23, 56-66. [CrossRef] [PubMed]

15. Burke, M.V.; Ebbert, J.O.; Hays, J.T. Treatment of tobacco dependence. Mayo Clin. Proc. 2008, 83, 479-483. [CrossRef] [PubMed]

16. Hughes, J.R.; Naud, S. Perceived role of motivation and self-efficacy in smoking cessation: A secondary data analysis. Addict. Behav. 2016, 61, 58-61. [CrossRef] [PubMed]

17. Jardin, B.F.; Carpenter, M.J. Predictors of quit attempts and abstinence among smokers not currently interested in quitting. Nicotine Tob. Res. 2012, 14, 1197-1204. [CrossRef] [PubMed]

18. Jordan, H.; Hidajat, M.; Payne, N.; Adams, J.; White, M.; Ben-Shlomo, Y. What are older smokers' attitudes to quitting and how are they managed in primary care? An analysis of the cross-sectional English Smoking Toolkit Study. BMJ Open 2017, 7, e018150. [CrossRef]

19. Clark, M.A.; Rakowski, W.; Kviz, F.J.; Hogan, J.W. Age and stage of readiness for smoking cessation. J. Gerontol. B Psychol. Sci. Soc. Sci. 1997, 52, S212-S221. [CrossRef]

20. Kviz, F.J.; Clark, M.A.; Crittenden, K.S.; Freels, S.; Warnecke, R.B. Age and readiness to quit smoking. Prev. Med. 1994, 23, 211-222. [CrossRef]

21. Buckland, A.; Connolly, M.J. Age-related differences in smoking cessation advice and support given to patients hospitalised with smoking-related illness. Age Ageing 2005, 34, 639-642. [CrossRef] [PubMed]

22. Morrow, M.; Barraclough, S. Tobacco control and gender in south-east Asia. Part II: Singapore and Vietnam. Health Promot. Int. 2003, 18, 373-380. [CrossRef] [PubMed]

23. Jenkins, C.N.; Dai, P.X.; Ngoc, D.H.; Kinh, H.V.; Hoang, T.T.; Bales, S.; Stewart, S.; McPhee, S.J. Tobacco use in Vietnam. Prevalence, predictors, and the role of the transnational tobacco corporations. JAMA 1997, 277, 1726-1731. [CrossRef] [PubMed]

24. Trotter, L.; Wakefield, M.; Borland, R. Socially cued smoking in bars, nightclubs, and gaming venues: A case for introducing smoke-free policies. Tob. Control 2002, 11, 300-304. [CrossRef] [PubMed]

25. Sciamanna, C.N.; Hoch, J.S.; Duke, G.C.; Fogle, M.N.; Ford, D.E. Comparison of five measures of motivation to quit smoking among a sample of hospitalized smokers. J. Gen. Intern. Med. 2000, 15, 16-23. [CrossRef] [PubMed]

26. Crittenden, K.S.; Manfredi, C.; Warnecke, R.B.; Cho, Y.I.; Parsons, J.A. Measuring readiness and motivation to quit smoking among women in public health clinics: Predictive validity. Addict. Behav. 1998, 23, 191-199. [CrossRef]

27. Berg, C.J.; Ling, P.M.; Hayes, R.B.; Berg, E.; Nollen, N.; Nehl, E.; Choi, W.S.; Ahluwalia, J.S. Smoking frequency among current college student smokers: Distinguishing characteristics and factors related to readiness to quit smoking. Health Educ. Res. 2012, 27, 141-150. [CrossRef]

28. Zhu, W.H.; Yang, L.; Jiang, C.Q.; Deng, L.Z.; Lam, T.H.; Zhang, J.Y.; Chan, S.S. Characteristics of smokers and predictors of quitting in a smoking cessation clinic in Guangzhou, China. J. Public Health 2010, 32, $267-276$. [CrossRef]

29. Tiffany, S.T.; Martin, E.M.; Baker, T.B. Treatments for cigarette smoking: An evaluation of the contributions of aversion and counseling procedures. Behav. Res. Ther. 1986, 24, 437-452. [CrossRef]

30. Lam, T.H.; Abdullah, A.S.; Chan, S.S.; Hedley, A.J.; Hong Kong Council on Smoking; Health Smoking Cessation Health Centre Steering Group. Adherence to nicotine replacement therapy versus quitting smoking among Chinese smokers: A preliminary investigation. Psychopharmacology 2005, 177, 400-408. [CrossRef]

31. de Vries, H.; Backbier, E. Self-efficacy as an important determinant of quitting among pregnant women who smoke: The phi-pattern. Prev. Med. 1994, 23, 167-174. [CrossRef] [PubMed]

32. Ershoff, D.H.; Quinn, V.P.; Boyd, N.R.; Stern, J.; Gregory, M.; Wirtschafter, D. The Kaiser Permanente prenatal smoking-cessation trial: When more isn't better, what is enough? Am. J. Prev. Med. 1999, 17, 161-168. [CrossRef] 
33. Tsang, I.K.; Tsoh, J.Y.; Wong, C.; Le, K.; Cheng, J.W.; Nguyen, A.N.; Nguyen, T.T.; McPhee, S.J.; Burke, N.J. Understanding and use of nicotine replacement therapy and nonpharmacologic smoking cessation strategies among Chinese and Vietnamese smokers and their families. Prev. Chronic Dis. 2014, 11, E26. [CrossRef] [PubMed]

34. West, R. Tobacco smoking: Health impact, prevalence, correlates and interventions. Psychol. Health 2017, 32, 1018-1036. [CrossRef]

35. Parsons, H.M. What Happened at Hawthorne? New evidence suggests the Hawthorne effect resulted from operant reinforcement contingencies. Science 1974, 183, 922-932. [CrossRef] [PubMed]

(C) 2018 by the authors. Licensee MDPI, Basel, Switzerland. This article is an open access article distributed under the terms and conditions of the Creative Commons Attribution (CC BY) license (http:/ / creativecommons.org/licenses/by/4.0/). 